\title{
Liver disease in childhood: principles of management
}

\author{
ROGER WILLIAMS \\ M.D., F.R.C.P.

\begin{abstract}
Director of Liver Research Unit and Consultant Physician, King's College Hospital and Medical School, Denmark Hill, London
\end{abstract}

THE first principle that we should agree to adopt is that each new treatment has to be assessed in a controlled manner. In the field of paediatric liver disease, even more than in adults, there is a dearth of properly controlled observations. But this is an aspect which subsequent speakers will be stressing. You have only to look at the management of infectious hepatitis in different parts of the world. In England it is regarded as a rather trivial illness. When it presents as a gastrointestinal disturbance, as it so often does in children, it is treated symptomatically by the G.P. and stools are allowed to pass down the usual family toilet without too much worry. Perhaps it is not surprising that cases can subsequently appear in other members of the family. Unfortunately when this occurs, the mother particularly may have a much more severe illness. Contrast this with the situation in Russia where every case of acute viral hepatitis is admitted to hospital, whatever the severity of the symptoms. Furthermore, children at school receive prophylactic gammaglobulin injections every alternate year.

Perhaps there is less disagreement around the world concerning the management of chronic hepatitis, at least of that variety which has been termed by the histopathologists 'chronic aggressive hepatitis', but which is known to the clinicians as active chronic hepatitis. This progresses to cirrhosis quite rapidly, and in many cases cirrhosis is already present at the time of diagnosis. Few would disagree that in this condition, long-term treatment with prednisone will prolong survival as well as improving clinical and biochemical features. But there is one problem, the distinction of this type of chronic hepatitis from another variety, known as chronic persistent hepatitis, in which progressive liver disease is said not to occur and which is usually allowed to resolve spontaneously. However, there are some patients with apparently well-documented chronic persistent hepatitis who over the course of a few years have progressed to active chronic hepatitis. So perhaps another principle of management is that patients with chronic hepatitis should be followed carefully, whatever their initial categorization.
But the most important of all principles of management must surely be to avoid making mistakes in diagnosis where specific therapy is a possibility. One patient of Dr Gamsu's, a young girl, was admitted with severe jaundice and died after a few weeks as a result of haemorrhage from oeosphageal varices. We did in fact think she had Kayser-Fleischer rings, but this was disputed even by the ophthalmologists, although on final tissue copper analysis there was no doubt about the diagnosis of Wilson's disease. In addition to well-known modes of presentation, this condition can first manifest as a haemolytic jaundice, or with features similar to active chronic hepatitis. It is so easily overlooked. This is a matter of concern not only for the patient but also for his siblings. The sister of the above patient was subsequently treated with penicillamine after establishing that she was a homozygote for the condition, and she remains free of symptoms and signs.

\section{Relating to the use of prednisone and azathioprine in active chronic hepatitis}

The frequency with which significant side-effects occur with longterm corticosteroid therapy for active chronic hepatitis is also a problem. These include osteoporosis, recurrent infections, diabetes; and in childhood an additional and very significant one, namely, stunting of growth. The reasons for this have recently been clarified. At pharmacological doses many steroids including cortisol (hydrocortisone) and prednisolone (the active metabolite of prednisone) are bound to serum albumin and the lower the serum albumin the higher the percentage of unbound, biologically active steroid. In a survey of 240 medical inpatients receiving prednisone, the frequency of prednisone side-effects was found to be doubled (Lewis et al., 1971). Furthermore, in liver disease there is also evidence that the metabolism of prednisolone is impaired as a result of the hepatic dysfunction (Powell and Axelsen, 1972) and this could result in prolonged high blood levels of the drug. Thus, it is not surprising that children or adults with severe chronic liver disease will show sideeffects with doses of corticosteroids that rarely have these effects in those with normal liver function. 
Although the conversion of prednisone to its active metabolite prednisolone was thought to be unimpaired in liver disease, recent studies have shown that conversion may be incomplete (Powell and Axelsen, 1972). To use prednisolone rather than prednisone may therefore assure more reliable blood levels of active steroids.

Not surprisingly, the other immunosuppressive drug that is widely used in autoimmune diseases, namely, azathioprine, has also been tried in active chronic hepatitis. In two recent controlled trials, azathioprine alone has failed to control the disease (Soloway et al., 1972; Murray-Lyon, Stern and Williams, 1973). This may be because the immunosuppressive agent is not the parent substance but a metabolite of the drug produced in the liver. It is not certain which of the metabolites are responsible for its immunosuppressive activity (Elion, 1972), but the latter can be assayed in the serum by the rosette inhibition test (Bach and Dardenne, 1972). Using this test, various studies have shown only low titres of serum immunosuppressive activity following azathioprine administration in patients with hepatic parenchymal disease (Mitchell et al., 1970; Bach and Dardenne, 1972; Whelan and Sherlock, 1972). This may explain the poor results found when this drug is used alone in the treatment of active chronic hepatitis.

Another problem relates to the possible hepatotoxicity of azathioprine (Mistilis and Blackburn, 1967; Starzl et al., 1971). It may be impossible to distinguish this from deterioration in liver function due to progression of the disease. However, there has been little evidence of possible hepatotoxicity with doses of 75-100 mg/day. Although it may be pointless giving azathioprine to a patient with severe disturbance of liver function, if improvement can be effected by another agent such as prednisone, then azathioprine may be useful in maintaining remission in combination with prednisone, allowing the dose of the latter to be reduced, with a corresponding reduction in the frequency of side-effects.

\section{Relating to the presence of hepatitis $B$ antigen}

What principle should be adopted in dealing with patients with active chronic hepatitis who are found to have the hepatitis B antigen (HB Ag) in the serum? The percentage of such cases varies from series to series and in different parts of the world, but this is partly due to the different sensitivities of the various techniques used in the detection of the antigen. It does not seem to be present as frequently in the English-born subject as in those coming from the Mediterranean littoral. In our own series, which included a few children, there was no difference between the positive cases and those negative for the antigen in the clinical features, biochemical

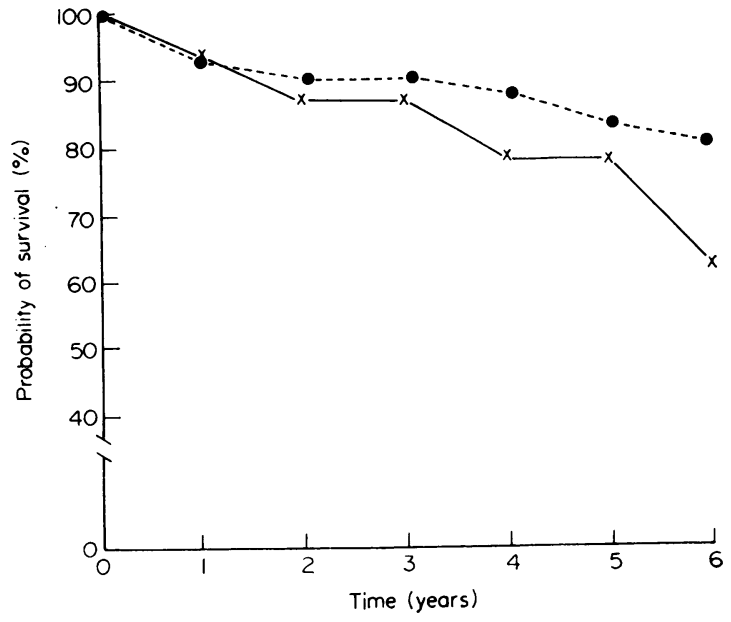

Fig. 1. Survival curves of $\mathrm{HB}$ Ag positive and negative cases of active chronic hepatitis. -, $\mathrm{HB} \mathrm{Ag}$ positive; --- , HB Ag negative.

changes, or in the markers of the immunological disorder (i.e. frequency and type of autoantibodies, pattern of immunoglobulin disturbance). The overall survival of the two groups was also very similar (Fig. 1), both groups having been treated in the same way with prednisone and/or azathioprine (Reed et al. 1973a). These findings would suggest that although infection by $\mathrm{HB} \mathrm{Ag}$ may have been the initiating factor in the illness, its persistence may not be of such importance in the pathogenesis of the continuing liver damage.

We may be able to answer this question, now that there is a possible means for eliminating or at least

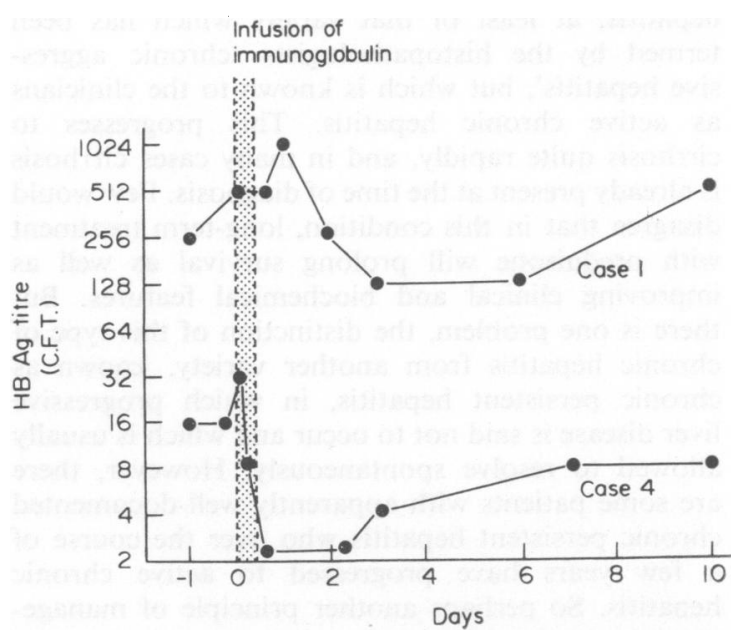

Fig. 2. Use of hyperimmune serum in two patients with $\mathrm{HB} \mathrm{Ag}$ positive active chronic hepatitis (from Reed et al., 1973b). 
reducing the titre of $\mathrm{HB} \mathrm{Ag}$ in the serum of these patients. Figure 2 shows results in two adults with active chronic hepatitis who received an i.v. infusion of an immunoglobulin containing a significant titre of antibody to HB Ag (Reed et al., 1973b). In the patient with the lower titre of $\mathrm{HB} \mathrm{Ag}$ initially, the antigen did disappear from the circulation for a time. Whether immunoglobulin given repeatedly or in higher concentration could lead to elimination of virus from such cases, and whether this would be beneficial to the patient, remains to be determined.

\section{Principles relating to fulminant hepatic failure}

There are particularly severe forms of hepatitis in which hepatic encephalopathy develops and which are included under the definition of fulminant hepatic failure. We are going to extrapolate very freely from the adult to the child. Figure 3 shows the causes in our series of patients: only those who

$\begin{array}{lrl}\text { Viral hepatitis } & & \\ \text { presumed infectious } & 38 & \\ \text { serum } & 7 & \\ \text { Paracetamol overdose } & 31 & \\ \text { Halothane associated } & 12 & \\ \text { Others } & 4 & \\ & \text { Total } 92 & \text { Alive } 10(11 \%)\end{array}$

FIG. 3. Causes of fulminant hepatic failure, Grade III or IV coma: the few children seen, most of whom had a presumed viral hepatitis, were excluded from this analysis. (King's College Hospital, January 11969 to September 1 1973.)

progressed to Grade III or Grade IV hepatic encephalopathy are included. The commonest cause was acute infectious hepatitis (type A), but this diagnosis, as is known to all, is one made largely by default. How can this type of hepatitis, usually so benign, on rare occasions take such a different course? You have already heard about a halothaneassociated case in a child. However, we have not yet seen fulminant hepatic failure due to an overdose of paracetamol in a child, though one is surprised that children have not swallowed the paracetamol tablets of their parents, in the same way that they have swallowed contraceptive pills, iron tablets and other necessities of modern day life!

Appropriate management in these patients can only be based on an understanding of the way in which the various signs and symptoms making up the clinical syndrome development during the course of the illness. Basic supportive therapy is essential, whatever other measures are used, and the importance of intensive monitoring to detect complications at an early stage cannot be over-emphasized (Williams, 1972).
The patient should be nursed in an intensive care ward, or better in a separate liver failure unit with adequate facilities for dealing with hepatitis B infection and for the prevention of cross-infections. The unconscious state and inadequate ventilation favour respiratory infection, and the need for intravenous infusion and a urinary catheter predispose to infections by these routes. A gram-negative septicaemia is a particular hazard.

Let us consider very briefly recent developments in the management of the haemorrhagic diathesis of fulminant liver failure which ranks only second in importance to encephalopathy. Not only is major bleeding from the gastrointestinal tract often the immediate cause of death, but earlier episodes of bleeding because of ensuing hypotension must almost certainly have deleterious effects on cerebral and renal function, as well as causing further ischaemic damage to the hepatocytes.

Study of the coagulation tests found on admission in our patients with fulminant hepatic failure (Fig. 4) showed that, as in other series, the prothrombin time was usually considerably prolonged and the fibrinogen concentration was often reduced. These changes could be due solely to failure of synthesis by the liver, but in addition the platelet count was frequently reduced, despite apparently normal production in the marrow. This was one of the observations that led us to suggest that intravascular coagulation was also occurring in these patients, with an increased

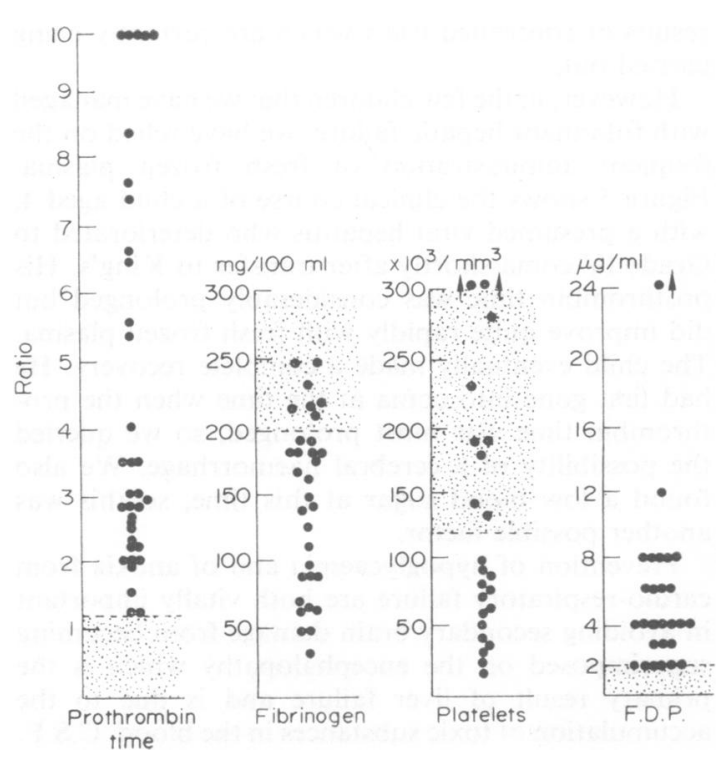

FIG. 4. Results of standard coagulation tests in thirtyseven patients with fulminant hepatic failure on admission to the Liver Unit. 
consumption of platelets and coagulation factors Intravascular fibrin formation would be expected to be followed, as in other clinical situations, by secondary fibrinolysis, and of this we found evidence with increased plasma levels of fibrinolytic digestion products.

The development of intravascular coagulation is presumably due to the release of tissue thromboplastins into the circulation from necrotic hepatocytes. In a series of patients with paracetamolinduced hepatic damage some relationship could be detected between changes indicative of intravascular coagulation and the severity of liver damage (Clark et al., 1973b). Furthermore, measurement of the plasma disappearance rate of radioactive fibrinogen shows it to be increased, whereas it would be normal or slightly slowed if there was a defect in hepatic synthesis alone. In addition, we have shown that the administration of heparin can be followed by a return of the catabolic rate towards normal.

We therefore attempted to control the coagulation disturbance by a combination of heparin for the intravascular coagulation and fresh frozen plasma in replacement for the synthetic defect (Rake et al., 1971). Such therapy has been followed by a remarkably rapid fall in prothrombin time and a rise in plasma fibrinogen level. Comparison with a previous series treated by replacement therapy alone appeared to show that the addition of heparin, as well as providing better control of the coagulation defect, reduced the severity of clinical bleeding (Clark et al., 1973). But whether this is truly so must await the results of controlled trials which are currently being carried out.

However, in the few children that we have managed with fulminant hepatic failure, we have relied on the frequent administration of fresh frozen plasma. Figure 5 shows the clinical course of a child aged 4, with a presumed viral hepatitis who deteriorated to Grade IV coma shortly after transfer to King's. His prothrombin time was considerably prolonged but did improve quite rapidly with fresh frozen plasma. The child eventually made a complete recovery. He had first gone into coma at the time when the prothrombin time was most prolonged, so we queried the possibility of a cerebral haemorrhage. We also found a low blood sugar at this time, so this was another possible factor.

Prevention of hypoglycaemia and of anoxia from cardio-respiratory failure are both vitally important in avoiding secondary brain damage from becoming superimposed on the encephalopathy which is the primary result of liver failure and is due to the accumulation of toxic substances in the blood, C.S.F. and brain (Williams, 1973; Curzon et al., 1973). The latter will improve only as the liver function recovers. But here we begin to get into the complicated areas of

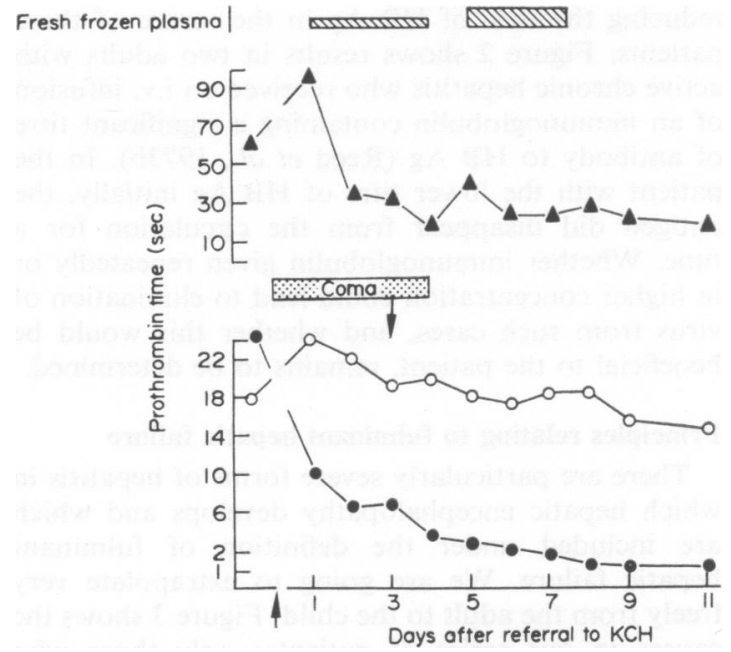

Fig. 5. Illustrating the course of a child with fulminant hepatic failure who finally made a complete clinical recovery. $\bigcirc-\bigcirc$, bilirubin $(\mathrm{mg} / \mathrm{dl}) ;-1$, AST $\times 10^{-2}$ (i.u./l); , I.P. male, Age 4, prednisone $40 \mathrm{mg} /$ day.

how to support these patients until regeneration of the liver will occur, i.e. exchange transfusion (of noo value in the one controlled trial carried out), pigliver perfusion, artificial liver support systems, and so on.

We must stress one difference between the syndrome of fulminant hepatic failure as seen in the child and that in the adult, namely the different survival rate. This came out very clearly in the Fulminant Hepatic Surveillance Study that Trey and colleagues in Boston have carried out. They now have data relating to 560 cases in their study (Trey, 1973). The survival figure for those who were under 14 years of age was $27.4 \%$, whereas for those between 15 and 45 years it was $19 \%$, and over the age of 45 years only $5 \%$ survived. This highlights one further principle, that there may be important differences between apparently similar diseases in childhood and adult life, and one of the fruits of the close collaboration that exists between the Liver Unit and the Department of Child Health at King's will be further knowledge in this important area.

\section{References}

BACH, J.-F. \& DARDENNE, M. (1972) Serum immunosuppressive activity of azathioprine in normal subjects and patients with liver disease. Proceedings of the Royal Society of Medicine, 65, 260.

Clark, R., Rake, M.O., Flute, P.T. \& Williams, R. (1973) Coagulation abnormalities in acute liver failure: pathogenetic and therapeutic implications. Scandinavian Journal of Gastroenterology, 8, suppl. 19, 63.

Clark, R., Borirakchanyavat, V., Rake, M.O., Shilkin, K.B., Flute, P.T. \& Williams, R. (1973b) Disordered haemostasis in liver damage from paracetamol overdose. Gastroenterology, 65, 788. 
Curzon, G., Kantameneni, B.D., Winch, J., Rojas-Bueno, A., Murray-Lyon, I.M. \& Williams, R. (1973) Plasma and brain tryptophan changes in experimental acute hepatic failure. Journal of Neurochemistry, 21, 137.

Elion, G.B. (1972) Significance of azathioprine metabolites. Proceedings of the Royal Society of Medicine, 65, 257.

LeWIS, G.P., Jusko, W.J., BuRKe, C.W. \& Graves, L. (1971) Prednisone side-effects and serum protein levels. Lancet, ii, 778.

Mistilis, S.P. \& BlackBuRN, C.R.B. (1967) The treatment of active chronic hepatitis with 6-mercaptopurine and azathioprine. Australasian Annals of Medicine, 16, 305.

Mitchell, C.G., Eddleston, A.L.W.F., Smith, M.G.M. \& Williams, R. (1970) Serum immunological activity due to azathioprine and its relation to hepatic function after liver transplantation. Lancet, i, 1196.

Murray-Lyon, I.M., Stern, R.B. \& Williams, R. (1973) Controlled trial of prednisone and azathioprine in active chronic hepatitis. Lancet, i, 735.

Powell, L.W. \& Axelsen, E. (1972) Corticosteroids in liver disease: studies on the biological conversion of prednisone to prednisolone and plasma protein binding. Gut, 13, 690 .

Rake, M.O., Shilkin, K.B., Winch, J., Flute, P.T., LeWis, M.L. \& Williams, R. (1971) Early and intensive therapy of intravascular coagulation in acute liver failure. Lancet, ii, 1215 .

ReED, W.D., Eddleston, A.L.W.F., Stern, R.B., Williams, R., Zuckerman, A.J., Baines, A. \& EARL, P. (1973a)
Radioimmunoassay for the detection of hepatitis B antigen in chronic liver disease and hepatocellular carcinoma in Great Britain. Lancet, ii, 690.

Reed, W.D., Eddleston, A.L.W.F., Cullens, H., Williams, R., Zuckerman, A.J., Peters, D.K., Williams, D.G. \& d'A. MAYCOCK, W. (1973) The effects of administration of hepatitis $B$ antibody in antigen positive active chronic hepatitis. Lancet, ii, 1347.

Soloway, R.D., Summerskill, W.H.J., Baggenstoss, A.H., Geall, M.G., Gitnick, G.L., Elveback, L.R. \& SchoenFIELD, L.J. (1972) Clinical, biochemical and histological remission of severe chronic active liver disease: a controlled study of treatments and early prognosis. Gastroenterology, 63, 820.

Starzl, T.E., Halgrimson, C.G., Penn, I., Martineau, G., Schroter, G., Amemiya, H., Putnam, C.N. \& Groth, C.G. (1971) Cyclophosphamide and human organ transplantation. Lancet, ii, 70.

TREY, C. (1973) The fulminant hepatic failure surveillance study. In: Liver (Ed. by S. J. Saunders and S. J. Terblanche), pp. 120-121. Pitman Medical, London.

Whelan, G. \& Sherlock, S. (1972) Immunosuppressive activity in patients with active chronic hepatitis and primary biliary cirrhosis treated with azathioprine. Gut, 13, 907.

Williams, R. (1972) Problems of fulminant hepatic failure. British Medical Bulletin, 28, 114.

Williams, R. (1973) Hepatic encephalopathy. Journal of the Royal College of Physicians of London, 8, 63.

\section{Discussion}

Professor Krugman expressed concern that in many cases of fulminant hepatitis a diagnosis of infectious hepatitis had been made while very few patients were considered to have serum hepatitis. He suggested it would be very helpful if serum specimens from these patients could be saved so that as new tests became available for antigen or anticore or coat antibody, it may be possible to extract some of the patients from the infectious hepatitis category and attribute them to serum hepatitis. Dr Cossart, too, felt that the infectious hepatitis label was used too frequently, particularly, in the surprisingly large proportion of middle-aged females who appear to suffer from severe hepatitis. It seemed likely that most of these subjects would have been exposed to infectious hepatitis in childhood and to have acquired immunity. Dr Williams agreed with both comments and pointed out that serum from most of these patients had been studied for hepatitis B antigen by Professor Zuckerman using techniques which included radioimmunoassay. In answer to a question from Dr Dubois on the importance of serum fetoprotein concentration in assessing the prognosis in fulminant hepatitis, Dr Williams regretted that it had not been possible to measure this factor in the cases discussed. At present it is postulated that as the liver regenerates, fetoprotein will appear in the serum-if this were substantiated it would be of great importance. The whole question of the management of fulminant hepatic failure resolves on hepatic regeneration. Clearly if one had a test which indicated that this was taking place, one should really go all out in trying to keep the patient alive.

In answer to another question, Dr Williams stated that none of the cases in the study had developed aplastic aniemia but when this occurred, the prognosis was very poor. 